\title{
Adherence with early infant feeding and complementary feeding guidelines in the Cork BASELINE Birth Cohort Study
}

\author{
Sinéad M O'Donovan ${ }^{1}$, Deirdre M Murray ${ }^{2,3}$, Jonathan O'B Hourihane ${ }^{2}$, \\ Louise C Kenny ${ }^{3,4}$, Alan D Irvine ${ }^{5,6,7}$ and Mairead Kiely ${ }^{1,3, *}$ \\ 'Vitamin D Research Group, School of Food and Nutritional Science, University College Cork, Cork, Republic of \\ Ireland: ${ }^{2}$ Department of Paediatrics and Child Health, University College Cork, Cork, Republic of Ireland: ${ }^{3}$ The Irish \\ Centre for Fetal and Neonatal Translational Research, University College Cork, Cork, Republic of Ireland: \\ ${ }^{4}$ Department of Obstetrics and Gynecology, University College Cork, Cork, Republic of Ireland: ${ }^{5}$ Department of \\ Clinical Medicine, Trinity College, Dublin, Republic of Ireland: ${ }^{6}$ Department of Pediatric Dermatology, Our Lady's \\ Children's Hospital, Dublin, Republic of Ireland: ${ }^{7}$ National Children's Research Centre, Dublin, Republic of Ireland
}

Submitted 14 July 2014: Final revision received 11 November 2014: Accepted 16 December 2014: First published online 18 February 2015

\begin{abstract}
Objective: To describe adherence with infant feeding and complementary feeding guidelines.

Design: Prospective study of infant feeding and complementary feeding practices were collected as part of the Cork BASELINE Birth Cohort Study.

Setting: Cork, Ireland.

Subjects: Data are described for the 823 infants for whom a diary was completed. Results: Breast-feeding was initiated in $81 \%$ of infants, and $34 \%, 14 \%$ and $1 \%$ of infants were exclusively breast-fed at hospital discharge, 2 and 6 months, respectively. Stage one infant formula decreased from $71 \%$ at 2 months to $13 \%$ at 12 months. The majority of infants (79\%) were introduced to solids between 17 and 26 weeks and $18 \%$ were given solid foods before 17 weeks. Mothers of infants who commenced complementary feeding prior to 17 weeks were younger (29.8 v. 31.5 years; $P<0.001)$ and more likely to smoke (18v. 8\%; $P=0.004)$. The first food was usually baby rice (69\%), infant breakfast cereals (14\%) or fruit/vegetables (14\%). Meals were generally home-made (49\%), cereal-based (35\%), manufactured (10\%), dairy (3\%) and dessert-based (3\%). The median gap between the first-second, second-third, third-fourth and fourth-fifth new foods was 4, 2, 2 and $2 \mathrm{~d}$, respectively.

Conclusions: We present the largest prospective cohort study to date on early infant feeding in Ireland. The rate of breast-feeding is low by international norms. Most mothers introduce complementary foods between 4 and 6 months with lengthy gaps between each new food/food product. There is a high prevalence of exposure to infant breakfast cereals, which are composite foods, among the first foods introduced.
\end{abstract}

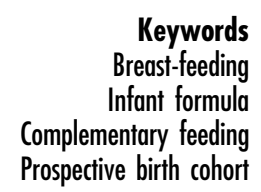

Nutrition from conception to 2 years is considered by the UN Standing Committee on Nutrition to be a critical period when the foundation for lifelong health is established ${ }^{(1)}$. The WHO globally recommends exclusive breast-feeding for 6 months, with partial breast-feeding and complementary foods thereafter ${ }^{(2)}$, while in Europe breast-feeding for the first 6 months is a desirable goal ${ }^{(3)}$. The WHO recommendation was subsequently supported by the American Academy of Pediatrics ${ }^{(4)}$ and was reviewed in 2012 with no amendments ${ }^{(5)}$. In the UK, although the Scientific Advisory Committee on Nutrition endorsed the WHO statement on breast-feeding, the expert group noted that there should be some flexibility in the advice as the introduction of solid foods earlier than 6 months is normal practice in the UK and mothers do this for many valid personal, social and economic reasons ${ }^{(6)}$. In Ireland, the WHO recommendations were endorsed by the Department of Health and Children in $2003^{(7)}$. In 2005, the Department of Health and Children published Breastfeeding in Ireland: A Five-year Strategic Action Plan, which further supported the WHO recommendations $^{(8)}$. In several countries, including Ireland and the UK, many infants are not exclusively breast-fed ${ }^{(9-12)}$ and therefore it is important that there are data available on infant formula-feeding practices. 
Complementary feeding is the provision of any nutrientcontaining foods or liquids other than breast milk and includes both solid foods and infant formula ${ }^{(13)}$. Many debates have ensued among those in developed countries about the appropriate time to first introduce solid foods to infants in these nations ${ }^{(14,15)}$. Initial reports found an increased risk of eczema among those given solids before 4 months ${ }^{(16-18)}$; however, the evidence since has been inconsistent. In 2008, recommendations in Europe ${ }^{(3)}$ and North America ${ }^{(19)}$ could not identify a definitive role of solid foods in the development of allergies as studies proved to be inconclusive and therefore amended their guidelines. Both authoritative organizations concluded that the introduction of solid foods should be between 4 and 6 months of age ${ }^{(3,19)}$. In 2013, the American Academy of Asthma, Allergies and Immunology offered a practical guide for complementary feeding for the primary prevention of allergic disease ${ }^{(20)}$, stating that solid foods should be introduced between 4 and 6 months and that major allergenic food ingredients could also be introduced at this time. In 2014, the European Academy of Allergy and Clinical Immunology concluded that there is still little evidence to support the delayed introduction of solid foods to protect against food allergy and that much is still to be learnt about food allergies, particularly in the area of early infant feeding ${ }^{(21)}$.

Until recently, few data have been available on early infant feeding practices in Ireland ${ }^{(22)}$. Between 2004 and 2006, 401 infants were prospectively followed through 6 months of age. Breast-feeding initiation rates were shown to be low $(47 \%)^{(9)}$ and a high proportion of infants were prematurely $(23 \%, \leq 12$ weeks) introduced to solid foods and provided with inappropriate supplementary fluids $(82 \%)^{(19)}$. Given this background, relevant objectives of Ireland's first prospective birth cohort (Cork BASELINE) were to: (i) document current infant feeding practices; (ii) examine complementary feeding patterns; (iii) identify the factors associated with early complementary feeding; and (iv) determine the different types, quantities and textures of foods consumed.

\section{Methods}

\section{Study design}

Data from the ongoing prospective Cork BASELINE (Babies After Scope: Evaluating the Longitudinal Impact Using Neurological and Nutritional Endpoints) Birth Cohort Study were analysed from birth through to 12 months. The SCOPE (Screening for Pregnancy Endpoints) study is a global, multicentre, longitudinal cohort study of low-risk primparous women, with the main aim of developing screening tests for the major diseases of late pregnancy ${ }^{(23)}$. SCOPE Ireland commenced recruitment in Cork in March $2008^{(24,25)}$. Cork BASELINE Birth Cohort Study was conducted according to the guidelines laid down in the Declaration of Helsinki and all procedures were approved by the Clinical Research Ethics Committee of the Cork Teaching Hospitals (reference number ECM 5 (9) $01 / 07 / 2008$ ). Written informed consent was obtained at 20 weeks' gestation or at birth.

\section{Data collection}

Detailed assessments were carried out on infants at day 2 and at 2, 6 and 12 months, with all 12-month assessments completed by December 2012; a cohort description is provided by O'Donovan et al. ${ }^{(26)}$. Parents would have received standard advice on infant feeding at prenatal parent-craft classes and were not provided by study staff with specific advice on infant feeding guidelines; if this was requested, the researchers provided general advice as endorsed nationally ${ }^{(27)}$. In November 2012, revised infant feeding guidelines were published by the Food Safety Authority of Ireland ${ }^{(28)}$; however, all infants had been introduced to solid foods before this edition was published. In the UK, the Diet and Nutrition Survey of Infants and Young Children (DNSIYC) report provides the only source of high-quality nationally representative data on the types and quantities of foods consumed by infants aged 4-18 months ${ }^{(11)}$ and as early infant feeding guidelines in Ireland are similar to those in the UK, comparisons between the DNSIYC report and the data presented here are discussed.

Definitions for the current paper include the following: (i) 'exclusive breast-feeding' refers to breast milk only, with infants receiving no water, infant formula or supplementary fluids; (ii) 'predominant breast-feeding' refers to breast milk as the main source of nutrition but infants may have received infant formula 'top-ups' at some stage (post-delivery awaiting the increase in milk volume or while mothers were on medication); and (iii) 'supplementary fluids' refers to any fluid (which includes water, sugary drinks, fruits juices or teas/infusions) consumed by the infant that was not breast milk, infant formula, vitamins or medication.

At the 2-month assessment, parents were provided with a pre-piloted 'weaning' diary and instructed to record information prospectively for the first 6 weeks of complementary feeding once their infant commenced solid foods, documenting type and quantity consumed. This was not a quantitative diary; the aim of the diary was to capture food exposure. The diary contained an instruction page and an example of how the diary was to be filled in at each feeding occasion. Information required included: (i) date and time of each feeding occasion; (ii) a food description (if home-made the method of preparation (steamed and puréed) was required or if commercially bought the brand was required); and (iii) the number of teaspoons consumed at each eating occasion. A small proportion of parents had not introduced solid foods by the 6-month assessment; therefore, a self-addressed envelope was given to parents to post back the complementary feeding diary once a period of 6 weeks on solid foods had been completed. Detailed 
Table 1 Variables extracted from the Cork BASELINE database and complementary feeding diaries used in the present analysis

\begin{tabular}{|c|c|}
\hline & Variables \\
\hline \multicolumn{2}{|l|}{ Cork BASELINE database } \\
\hline $\begin{array}{l}\text { Maternal characteristics } \\
\text { and health }\end{array}$ & $\begin{array}{l}\text { - Age at birth } \\
\text { - Type of maternity care } \\
\text { - Marital status } \\
\text { - Race } \\
\text { - Country of birth } \\
\text { - School years } \\
\text { - University education } \\
\text { - Employment status } \\
\text { - Income } \\
\text { - Census } 2006 \text { major group } \\
\text { - Smoking status } \\
\text { - Mode of delivery } \\
\text { - Self-reported allergies (and paternal) }\end{array}$ \\
\hline $\begin{array}{l}\text { Infant characteristics, } \\
\text { feeding and clinical data }\end{array}$ & $\begin{array}{l}\text { - Gender } \\
\text { - Gestational age } \\
\text { - Feeding at discharge, 2, } 6 \text { and } 12 \text { months } \\
\text { - Supplementary fluids } \\
\text { - Food textures and age first tried }\end{array}$ \\
\hline Complementary feeding diary & $\begin{array}{l}\text { - Date of weaning } \\
\text { - First five foods introduced } \\
\text { - Gap between each new food (d) } \\
\text { - Quantity of food (spoons) } \\
\text { - Allergenic food ingredients (cow's milk, wheat, soya, fish, shellfish, } \\
\text { - eggs, peanuts and tree nuts) } \\
\text { - Number of different foods in the first } 6 \text { weeks and in the entire } \\
\text { - Proportion of meals that were vegetables, fruit, home-made, } \\
\text { commercial, cereal-based, gluten-containing, dairy-based or desserts }\end{array}$ \\
\hline
\end{tabular}

information on manufactured products was obtained for almost all products recorded in diaries. Data extracted from the database and the diaries used in the present analysis are described in Table 1.

\section{Statistical analysis}

A total of 823 women (57\% response rate) returned a completed diary. The mean duration of complementary feeding documented was 6 (SD 3.7) weeks. The instructed time of 6 weeks, to capture the introduction of solid foods, was adhered to by $53 \%$ with an additional $19 \%$ documenting 4 weeks. Statistical analysis of the data was conducted using PASW ${ }^{\circledR}$ Statistics version 20.0. Comparisons between those introduced to solids early (before 17 weeks) and after 17 weeks were performed using Pearson's $\chi^{2}$ test and the Mann-Whitney $U$ test, for categorical and continuous variables, respectively. Data are presented using numerical descriptive statistics, including means and standard deviations, medians with interquartile ranges (IQR), and frequencies with percentages.

\section{Results}

\section{Maternal and infant characteristics}

At birth, 1537 infants were eligible for postnatal follow-up and $94 \%$ completed the 2-month assessment. Postnatal assessments were completed at mean age of 67 (sD 11) d, 91 (sD 13) d and 382 (SD 16) d at 2, 6 and 12 months, respectively. Principal maternal and neonatal traits are illustrated in Table 2. Those who completed a diary were older (31 v. 29 years), more likely to have a partner (96 v. 91\%), to have obtained a university education (59v. $47 \%$ ) and to be nonsmokers (90 v. 82\%), all $P<0.001$, compared with those who did not complete a diary. In comparison to the DNSIYC report, there were higher proportions of Caucasian (82\%v. $99 \%)$ and married mothers (54\%v. $71 \%$ ) in the present study, although mothers were similar in age (mean $31 v .30$ years).

This cohort is not nationally representative as firsttime mothers with a singleton pregnancy were recruited exclusively from the Cork region and were more educated than groups reported elsewhere ${ }^{(29,30)}$; however, other sociodemographic and infant feeding characteristics compared well with national reports ${ }^{(26)}$.

\section{Feeding practices}

Breast-feeding was initiated in $81 \%$ of infants. At hospital discharge, $75 \%$ mothers were still breast-feeding, with 34\% exclusively and $41 \%$ predominantly breast-feeding their infants. At 2 months, 51\% ( $n$ 424), 31\% ( $n$ 251) and 18\% ( $n$ 148) were receiving infant formula, breast milk and combination-fed (both breast and formula daily), respectively. 
Table 2 Characteristics of the Cork BASELINE Birth Cohort Study participants, stratified by those who did or did not return a complementary feeding diary

\begin{tabular}{|c|c|c|c|c|c|}
\hline & $\begin{array}{l}\text { Cohort } \\
\text { (n 1537) }\end{array}$ & $\begin{array}{c}\text { Assessed at } 2 \text { months } \\
(\text { ( } 1443)\end{array}$ & $\begin{array}{l}\text { Diary returned } \\
\quad(n \text { 823) }\end{array}$ & $\begin{array}{c}\text { No diary returned } \\
(n \text { 620) }\end{array}$ & $P$ value ${ }^{*}$ \\
\hline \multicolumn{6}{|l|}{ Maternal characteristics } \\
\hline \multicolumn{6}{|l|}{ Maternal age (years) } \\
\hline Mean & 30.6 & $30 \cdot 6$ & 31.0 & 29.9 & \multirow{2}{*}{0.00001} \\
\hline $\mathrm{SD}$ & 4.4 & 4.4 & 3.8 & 4.9 & \\
\hline$\leq 24(\%)$ & 10 & 9 & 5 & 15 & 0.00000 \\
\hline $25-34(\%)$ & 74 & 74 & 79 & 69 & 0.00002 \\
\hline$\geq 34(\%)$ & 16 & 16 & 16 & 16 & 0.625 \\
\hline \multicolumn{6}{|l|}{ Education (\%) } \\
\hline$\geq 13$ years in school & 89 & 89 & 90 & 87 & 0.119 \\
\hline Ūniversity degree & 56 & 53 & 59 & 47 & 0.000006 \\
\hline \multicolumn{6}{|l|}{ Ethnicity (\%) } \\
\hline Caucasian & 98 & 98 & 99 & 97 & 0.017 \\
\hline \multicolumn{6}{|l|}{ Socio-economic status (\%) } \\
\hline Professional, managerial \& technical & 61 & 61 & 66 & 55 & 0.000045 \\
\hline Non-manual \& skilled & 28 & 28 & 25 & 32 & 0.004 \\
\hline Unskilled & 4 & 4 & 4 & 5 & 0.482 \\
\hline Unwilling to disclose & 7 & 7 & 5 & 8 & 0.029 \\
\hline \multicolumn{6}{|l|}{ Marital status (\%) } \\
\hline Partner & 94 & 94 & 96 & 91 & 0.00027 \\
\hline Smoker at 2 months (\%) & 13 & 13 & 10 & 18 & 0.000008 \\
\hline \multicolumn{6}{|l|}{ Mode of delivery (\%) } \\
\hline Vaginal & 74 & 72 & 73 & 72 & \multirow[t]{2}{*}{0.944} \\
\hline Caesarean & 26 & 28 & 27 & 28 & \\
\hline \multicolumn{6}{|l|}{ Neonatal characteristics } \\
\hline Gender male (\%) & 50 & 51 & 53 & 47 & 0.024 \\
\hline \multicolumn{6}{|l|}{ Gestation (weeks) } \\
\hline Median & $40 \cdot 3$ & $40 \cdot 0$ & $40 \cdot 3$ & $40 \cdot 2$ & \multirow[t]{2}{*}{0.093} \\
\hline IQR & $39-41$ & $39-41$ & $39-41$ & $39-41$ & \\
\hline$<37(\%)$ & 5 & 5 & 4 & 6 & 0.065 \\
\hline $37-41(\%)$ & 72 & 72 & 72 & 72 & 0.987 \\
\hline$>41(\%)$ & 23 & 23 & 24 & 22 & 0.351 \\
\hline \multicolumn{6}{|l|}{ Birth weight $(\mathrm{kg})$} \\
\hline Mean & 3.5 & 3.5 & 3.5 & $3 \cdot 4$ & \multirow[t]{2}{*}{0.042} \\
\hline $\mathrm{SD}$ & 0.5 & 0.5 & 0.5 & 0.6 & \\
\hline$\leq 2.5(\%)$ & 4 & 4 & 3 & 6 & 0.001 \\
\hline $2.51-4.49(\%)$ & 94 & 93 & 94 & 92 & 0.063 \\
\hline$\geq 4.5(\%)$ & 2 & 2 & 3 & 2 & 0.137 \\
\hline
\end{tabular}

IQR, interquartile range.

${ }^{*}$ Comparison between those who did and did not return a diary; analysis was performed by using Pearson's $X^{2}$ test for categorical variables and the MannWhitney $U$ test for continuous variables (two-sided significance).

At 2 months, $14 \%$ ( $n$ 120) were exclusively breast-fed. Of the infants formula-fed at 2 months, 157 (37\%) had never received breast milk. Of those who had ceased breastfeeding by 2 months, the median age of the infants at cessation was 14 (IQR 3-30) d. Stage one or standard infant formula (whey-based) was given to $71 \%$ of infants at 2 months, while $19 \%$ received a 'hungrier' infant formula (predominantly casein-based), 10\% received a specialized formula (lactose-free, pre-thickened or hydrolysed/hypoallergenic infant formula) and $1 \%$ received other formula (based on goat's milk or soya milk), see Fig. 1. Among the infants receiving infant formula at 2 months, the formula was switched at least once by $53 \%$ of mothers, with a further $15 \%$ changing formula at least twice. The main reasons for changing formula included: hungry baby (45\%); unsuitability (23\%); colic (9\%); reflux (7\%); constipation (6\%); vomiting ( $4 \%$ ); and advice of a health professional (6\%).

By 6 months, $74 \%$ of infants were given infant formula with solid foods, with $25 \%$ receiving breast milk in combination with infant formula, solids or both. Nine infants (1\%) were exclusively breast-fed to 6 months, of whom seven were born to Irish mothers. Standard infant formula was most often used (47\%) at 6 months, with $20 \%$ and $21 \%$ of infants provided with hungry baby and followon formula, respectively, see Fig. 1. At 12 months, $73 \%$ of infants were provided infant formula and $8 \%$ were still breast-fed in conjunction with solid foods. Of those receiving infant formula at 12 months (67\%), most were provided with a follow-on ( $41 \%$ ) or toddler (26\%) infant formula and $49 \%$ of infant formula was casein-dominant. Cow's milk was the sole source of milk for $15 \%$ of infants; while another $3 \%$ of infants were receiving cow's milk and infant formula.

Supplementary fluids were given to $62 \%$ (29\% breastfed and $33 \%$ formula-fed) of infants at 2 months. Most infants received (52\%) cooled boiled water while a quarter of infants received inappropriate fluids, which included glucose/sugary drinks (17\%), fruit juices (5\%) and herbal tea/infusions (4\%). At 6 months, $12 \%$ of infants were receiving solutions added to their milk feed, mostly medication or vitamins ( $8 \%)$. This trend continued at 


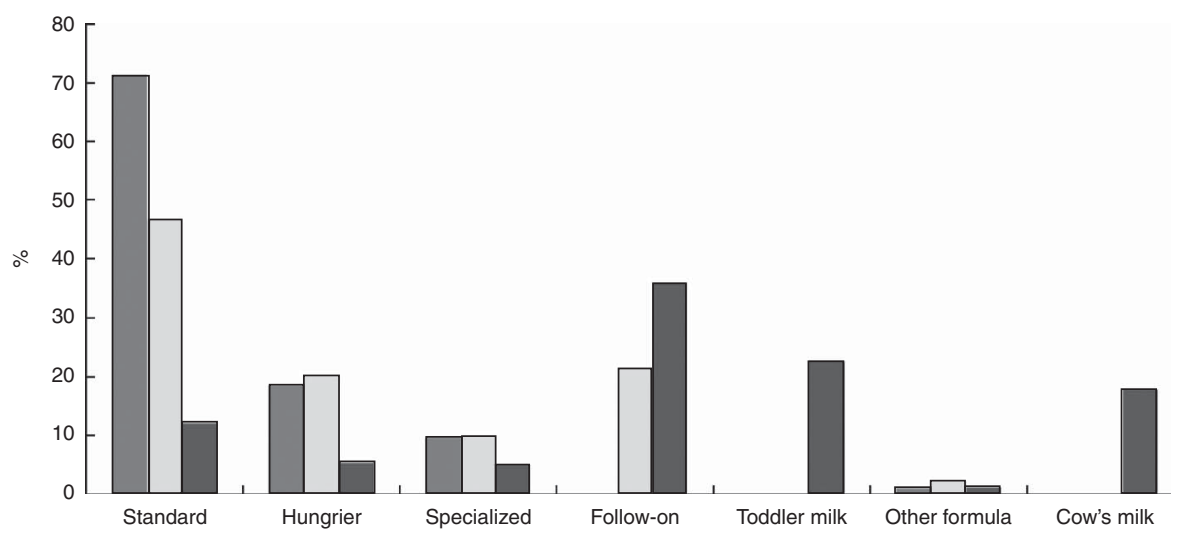

Fig. 1 Type of infant formula/cow's milk provided to infants participating the Cork BASELINE Birth Cohort Study at 2 ( $\square$ ), 6 ( $\square$ ) and 12 months ( $\square$ )

12 months. Throughout the first 12 months, other items added to milk feeds included infant cereal $(3 \%)$, water (1\%), herbal tea (1\%), juice ( $1 \%)$, sugar $(0 \cdot 2 \%)$ and breast milk $(0 \cdot 4 \%)$ or cow's milk (1\%).

\section{Complementary feeding}

Timing of solid food introduction

Seventy-nine per cent of mothers introduced complementary foods between 17 and 26 weeks of age. Of the $18 \%$ who were introduced to solid foods before 17 weeks, 28 and $44 \%$ were given solids at 15 and 16 weeks, respectively. Eleven infants were weaned before 12 weeks and $3 \%$ were weaned after 26 weeks. The main reasons for commencing complementary feeding included: hungry infant (43\%); recommendation of others (26\%; public health nurse (52\%), doctor (21\%), family member (19\%), friend (9\%)); and following specific complementary feeding guidelines (17\%), see Table 3. Mothers of infants who commenced complementary feeding prior to 17 weeks were younger (29.8 $v$. 31.5 years; $P<0.001$ ), less well educated (no university degree: $55 v .38 \% ; P<0.0001)$ and more likely to smoke (18 $v$. $8 \% ; P=0.004)$. Infants formula-fed at hospital discharge and at 2 months were more likely to be introduced to solids before 17 weeks than those provided with solids after 17 weeks.

\section{Complementary feeding foods}

Baby rice was predominantly used as the first food in $68 \%$ of infants, followed by infant breakfast cereals (14\%), other fruit and vegetables (7\%), carrots (5\%), apple (2\%) and other foods (including meat, fish, dairy, eggs and commercially available foods (4\%)), see Fig. 2. Fruit and vegetables were the predominant (66\%) second foods, with $5 \%$ receiving baby rice. For the third, fourth and fifth foods, fruit and vegetables were the dominant food items, followed by other foods and commercial infant breakfast cereals. In the 6-week period a range of 1-60 new food items (median: 12) were introduced. These food items were categorized into six different categories: (i) fruit and vegetables; (ii) infant breakfast cereals including baby rice; (iii) meat, fish and eggs; (iv) dessert-based meals; (v) baby foods; and (vi) dairy (yoghurt, fromage frais, cheese). The proportion of infants given one, two, three, four, five and all six categories was 3, 24, 25, 24, 16 and 6\%, respectively. Meat was given to $26 \%$ of infants, with 52,18 and $30 \%$ receiving white, red or both types of meat, respectively. The types of meals generally presented to infants in the first 6 weeks of complementary feeding were: home-made (49\%); manufactured products (45\%; $35 \%$ cereal-based and $10 \%$ baby foods); dairy (3\%); and dessertbased (3\%). Of the manufactured products offered, most contained an average of three different ingredients, with one product containing seven different ingredients; these products were the main source of new/different foods.

\section{Food consistency and quantity consumed}

Pureed food was the first texture introduced (range 832 weeks), with gradual progression to mashed food (range 16-52 weeks), followed by lumpy food (range 16-52 weeks) and then chopped food (range 17-56 weeks). At 6 months, puréed food was the most frequently presented (98\%), other textures were also offered that included mashed (47\%), lumpy (32\%) and chopped (9\%). By 12 months, few infants had still not progressed to mashed (1\%), lumpy (2\%) or chopped ( $8 \%$ ) foods. The quantity of food consumed at the very first eating occasion was 3 (IQR 2-5) teaspoons, which increased to 8 (IQR 4-15) and 15 (IQR 6-25) teaspoons daily after 2 and 6 weeks from the initial introduction of solids, respectively. There was a median gap of $4 \mathrm{~d}$ reported between the first and second new food, which decreased to $2 \mathrm{~d}$ between the second and third, third and fourth, fourth and fifth new foods, and $1 \mathrm{~d}$ thereafter.

\section{Discussion}

These data from the Cork BASELINE Birth Cohort Study are the most detailed and largest prospectively collected 
Table 3 Maternal and postnatal factors that influenced the age of complementary feeding among infants in the Cork BASELINE Birth Cohort Study

\begin{tabular}{|c|c|c|c|c|}
\hline & All $(n 823)$ & $<17$ weeks $(n 148)$ & $\geq 17$ weeks $(n 675)$ & $P$ value* \\
\hline \multicolumn{5}{|l|}{ Maternal age (years) } \\
\hline$\leq 25(\%)$ & 5 & 12 & 3 & 0.000001 \\
\hline \multicolumn{5}{|l|}{ Education (\%) } \\
\hline No university degree & 41 & 55 & 38 & 0.000001 \\
\hline \multicolumn{5}{|l|}{ Marital status (\%) } \\
\hline Partner & 96 & 93 & 98 & 0.019 \\
\hline Smoker (\%) & 10 & 18 & 8 & 0.000152 \\
\hline \multicolumn{5}{|l|}{$\begin{array}{l}\text { Reason for solid food } \\
\text { introduction }(\%) \dagger\end{array}$} \\
\hline Milk not enough & 43 & 57 & 40 & 0.00071 \\
\hline Other people & 26 & 21 & 26 & 0.168 \\
\hline Specific guidelines & 17 & 5 & 19 & 0.000022 \\
\hline Other & 14 & 17 & 39 & 0.309 \\
\hline Gender male (\%) & 53 & 54 & 53 & 0.797 \\
\hline \multicolumn{5}{|l|}{ Feeding (\%) } \\
\hline Formula at discharge & 24 & 41 & 21 & 0.00000 \\
\hline Formula at 2 months & 52 & 76 & 46 & 0.00000 \\
\hline \multicolumn{5}{|l|}{ Birth weight $(\mathrm{kg})$} \\
\hline Median & 3.5 & 3.5 & 3.5 & 0.433 \\
\hline IQR & $3 \cdot 2-3 \cdot 8$ & $3 \cdot 2-3 \cdot 8$ & $3 \cdot 2-3 \cdot 8$ & \\
\hline \multicolumn{5}{|l|}{ Gestational age (weeks) } \\
\hline Median & 40 & 40 & 40 & 0.460 \\
\hline IQR & $39-41$ & $39-41$ & $39-41$ & \\
\hline
\end{tabular}

IQR, interquartile range.

*Comparison between those introduced to solids at $<17$ weeks and $\geq 17$ weeks; Pearson's $x^{2}$ test was used for categorical variables and the Mann-Whitney $U$ test for continuous variables (two-sided significance).

†Milk not enough = mother believed milk feeds were no longer satisfying her infant; other people =influence of public health nurse, doctor, family member and friends; specific guidelines =WHO, Health Service Executive (Irish national health service); other = appropriate age, back to work, interested in and ready for food.

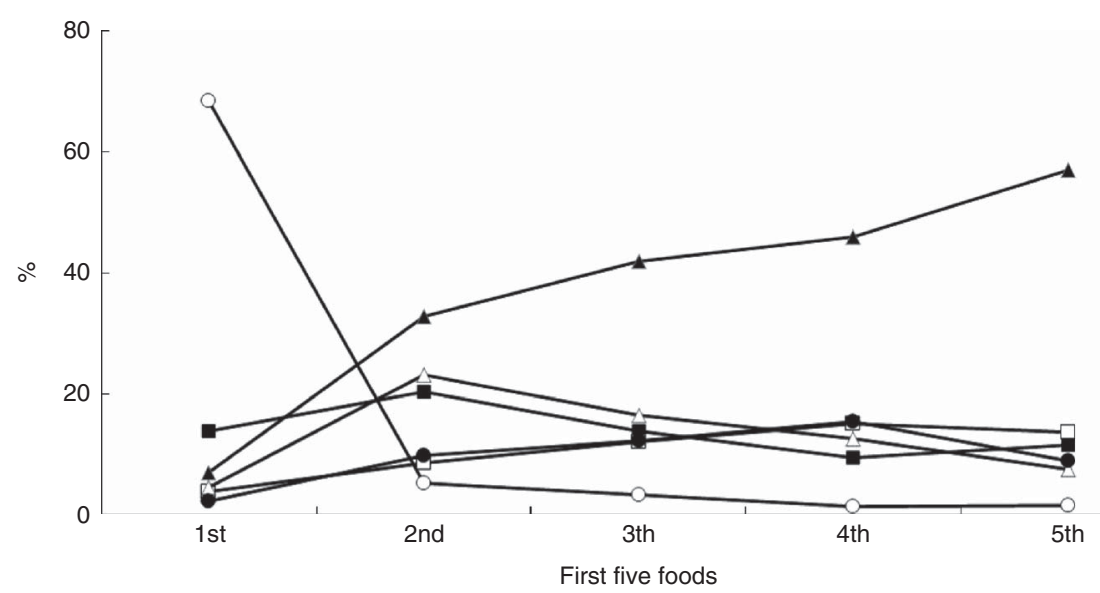

Fig. 2 Proportion of foods that were introduced as one of the first five foods (-o-, baby rice; $-\mathbf{-}-$, apple; $-\Delta-$, carrot; $-\mathbf{\Delta}-$, other fruits and vegetables; $-\square-$, other foods; $-\square-$, infant breakfast cereals) to infants in the Cork BASELINE Birth Cohort Study

longitudinal description of early infant feeding to date. We have shown that although the rate of breast-feeding initiation has increased $^{(9)}$, breast-feeding duration has not increased in Ireland. These trends are also reflected in the $\mathrm{UK}^{(11,12)}$. With respect to the introduction of solid foods, we have shown that this sample of first-time parents were broadly adherent with national ${ }^{(31)}$ and international recommendations on timing ${ }^{(3,19)}$. The practice of premature complementary feeding (before 12 weeks) was low, similar to recent UK data ${ }^{(11)}$. The provision of caseindominant as opposed to whey-dominant infant formula throughout year one among up to $49 \%$ of infants is noted, as is the persistence of cow's milk as a mainstay among $15 \%$ of infants. The use of composite foods (mainly 'infant breakfast cereals') as first foods is a concern as food items should be introduced one at a time. Evidence shows lengthy gaps between the introductions of new food items may compromise achievement of a varied complementary feeding diet.

In 1992, in recognition that the rate of breast-feeding at hospital discharge remained in the region of $30 \%$ from 1984 to $1990^{(32)}$, the Irish National Committee to Promote 
Breastfeeding was established with the aim to increase breast-feeding rates to $50 \%$ by the year $2000^{(33)}$. National reports in 2001, 2006 and 2010 revealed that the trend in breast-feeding rates continued to increase with 42, 49 and $54 \%$ breast-feeding at hospital discharge, respectively ${ }^{(29)}$. Our data found that $81 \%$ of mothers recruited initiated breast-feeding, although lower numbers sustained this to hospital discharge $(75 \%)$. According to national reports $74 \%$ of Irish mothers remain in hospital $2-5 \mathrm{~d}$ after delivery ${ }^{(29)}$ compared with $38 \%$ in the $\mathrm{UK}^{(34)}$, which may influence breast-feeding rates. Although breast-feeding initiation rates have improved, breast-feeding duration rates remain very short in the $\mathrm{UK}^{(11,12)}$ and Ireland ${ }^{(9)}$. Almost all mothers in the present study did not breast-feed exclusively to 6 months ${ }^{(2)}$. Our figures, along with those previously reported in Ireland ${ }^{(9)}$ and the $\mathrm{UK}^{(12)}$, demonstrate that little has changed over the past 30 years with respect to breast-feeding duration. Interestingly, an Irish study by Begley and colleagues ${ }^{(35)}$ found that $34 \%$ of women during the antenatal period had planned to formula-feed their infant. An Irish study found the antenatal period was an effective time for concentrating efforts to encourage women to breast-feed and that involving the partner and the maternal grandmother in breast-feeding initiatives appeared crucial to increase rates $^{(9)}$. Therefore, greater emphasis should be placed on the antenatal education of pregnant and pre-conceptual women regarding the benefits of breast-feeding.

For women who chose not to or are unable to breast-feed, current guidelines recommend the use of a standard infant formula (whey-dominant) throughout the first 12 months of life ${ }^{(31,36)}$. This type of formula is recommended as the ratio of whey to casein (60:40) is approximately that of human milk ${ }^{(36)}$. The DNSIYC report found $37 \%$ of infants aged $4-6$ months were provided with a standard infant formula, which decreased to $1 \%$ among infants aged 12-18 months $^{(11)}$; a similar trend was observed in the present study. According to the UNICEF Baby Friendly Initiative, there is no evidence that changing from whey-based formula to any other type of formula is necessary or beneficial. However, the various brands of infant formula available may differ from each other in processing and in sources and levels of protein, lipids and micronutrients, which may affect infant tolerance and may be improved by switching ${ }^{(36)}$. By 2 months, $53 \%$ of formula-fed infants had their infant formula changed at least once, with a hungry/unsatisfied baby prompting most changes as opposed to infant vomiting, colic or reflux, findings similar to a previous report ${ }^{(37)}$. Hungrier infant formulas are predominantly casein-based and in the present study, the use of casein-dominant formula increased with increasing age (20 to $49 \%$, from 2 to 12 months). The higher casein content causes larger, less easily digested curds to form in the stomach which is intended to make the baby feel full for longer ${ }^{(36)}$. Although the proportions of macronutrients are the same, the ratio of whey to casein
(20:80) in these formulas does not mimic human milk and for this reason they are not recommended for infants ${ }^{(36)}$. With a high proportion of Irish infants receiving caseindominant infant formula, the potential health outcomes associated with the use of such formula warrant further investigation.

Cow's milk is not recommended until 12 months of age due to the lack of essential nutrients, primarily Fe, and is also contraindicated due to an excess of some nutrients, namely protein and $\mathrm{Na}^{(3,31)}$. Data from the Avon Longitudinal Study of Parents and Children (ALSPAC) found that infants fed breast or cow's milk at 12 months, without infant formula, had a high risk of anaemia in later infancy ${ }^{(38)}$. Although $15 \%$ of infants were receiving cow's milk as the sole source of milk at 12 months, data on the time of commencing cow's milk were not recorded. Data on the type of cow's milk given (whole, semi-skimmed or skimmed) were not collected either; this would be interesting to elucidate as whole milk is recommended for infants of this age ${ }^{(28,31)}$.

Up to the age of 6 months, breast- or formula-fed infants generally do not need any supplementary fluids ${ }^{(31)}$. While formula-fed infants may be offered cooled boiled water, this does not apply to breast-fed infants, as offering other fluids may interfere with the demand-supply basis of milk production $^{(31)}$. By 2 months, $25 \%$ of infants in the present study were given a glucose/sugary drink, a fruit juice and/or a herbal tea/infusion; and these fluids are considered highly unsuitable as they can damage teeth along with reducing hunger for milk and spoon feeds ${ }^{(31)}$. An Irish study found that infants aged 6 months consumed a high proportion of baby juices $(57 \%)^{(22)}$. The addition of fluids or foods to infant bottles continues among Irish families as highlighted in the current study and another Irish report ${ }^{(19)}$, although mostly medication (50-70\%), infant cereal and sugar, among others, were added. The first National Infant Feeding Policy ${ }^{(28)}$ did not emphasis the risk associated with inappropriate fluids or with items being added to infant bottles. However, the new Irish National Infant Feeding policy highlights the risks and it will be important to evaluate if these recommendations are adopted ${ }^{(31)}$.

Baby rice has been consistently reported as the first food in the complementary feeding diet of European children ${ }^{(11,39-41)}$, which was replicated in the present study. Fruit and vegetables and infant breakfast cereals were the next most frequently presented first foods. Other foods (meat, fish, dairy, eggs) increased steadily as the transition to solid foods became more established. Current recommendations encourage home-prepared meals over readymade meals from an early age ${ }^{(27,31)}$ and these were prepared frequently (49\%) in the present study. Recent data have shown that exposure to home-prepared fruit and vegetables, rather than ready-prepared fruit and vegetables, during the complementary feeding process is a good indicator of later frequent consumption of fruit and vegetables $^{(42)}$. Home-made meals should be the main food 
offered to infants as poor eating habits established during early infant feeding can track into later childhood ${ }^{(42)}$.

Manufactured products (mainly infant breakfast cereals), which are composite foods, were given to a high proportion of infants and were the main source of exposure to a large number of new foods. European legislation (Article 8, EC Directive 2006/125/EC) regulates the labelling of infant foods, and according to EU regulations many complementary foods can be labelled as being suitable for infants from 4 months. However, some of these products are not in line with best infant feeding practices and similar foods prepared in the home would be considered unsuitable for infants ${ }^{(31)}$. Therefore, it is important to consider the role that labelling of such products may play in complementary feeding, which can undermine the advice given by health professionals, particularly among relatively disadvantaged groups who introduce solid foods early. In 2003, the Department of Health, England ${ }^{(43)}$ asked if food manufacturers could be persuaded to alter their labelling from 4 months to 6 months. At that time, the European Commission indicated that it intended to review the labelling of these foods but did not give a time frame for this work. As of 2014, no amendments have yet been made ${ }^{(44)}$.

National $^{(31)}$ and international ${ }^{(3,19)}$ guidelines specify the introduction of one new food at a time, allowing a few days between each new food so an adverse reaction can be easily pinpointed. Lengthy gaps between the introductions of each new food were observed in the present study, particularly between the first and second new food. The revised Irish national guidelines emphasize the introduction of a single ingredient at a time, rather than the previous phrase 'a new food' ${ }^{(31)}$. These new guidelines may be too exacting in that a varied diet may be difficult to achieve, particularly during this critical period of growth. Therefore, the introduction of a single ingredient at a time should perhaps be applied to the major allergenic foods instead of all food ingredients. However, much still needs to be learnt about the importance of allergenic food ingredients in the development of allergic disease ${ }^{(21)}$ and a recent systematic review highlighted that currently the evidence does not justify either withholding or encouraging potentially allergenic foods after 4 months, irrespective of atopic hereditary ${ }^{(45)}$.

Reports, from Ireland and the UK, suggest that the age of solid food introduction is increasing. However, a recent study in the UK demonstrated that primparous women are confused by the multiple sources of advice for complementary feeding, some of which seemed conflicting ${ }^{(46)}$. The DNSIYC report found that $32 \%$ of infants were introduced to solid foods before 4 months ${ }^{(11)}$ which supports the findings from the 2010 UK Infant Feeding Survey ${ }^{(12)}$ (31\%), in which they demonstrated $20 \%$ reduction in those fed before 4 months compared with 2005 (51 v. $31 \%$ ). Of the infants introduced to solid foods before 17 weeks in the present study, $72 \%$ were given solids at $15-16$ weeks; indicating that parents are waiting for the 4 month stage to introduce foods. In the UK, informal sources of information (Internet, family members) were most influential among younger mothers of lower educational attainment, which resulted in earlier transition to solid foods ${ }^{(46)}$. Several studies on complementary feeding have that shown less well educated mothers are more likely to introduce solid foods early than those who are well educated $^{(22,47,48)}$. Therefore, as complementary feeding patterns are similar between the UK and Ireland, health-care professionals need to provide more support to this vulnerable group of women in communicating complementary feeding guidelines.

In summary, in addition to an update on early infant feeding in Ireland, the current paper presents the largest and most detailed description of complementary feeding among 823 infants to date. As the transition to solid foods can be a difficult process for families ${ }^{(3)}$, our use of a non-weighed food diary to describe the first 6 weeks of complementary feeding allowed us a unique opportunity to record data in real time; with complete food descriptions including both home-made and commercial products. The main study limitation is that the birth cohort is not nationally representative; highly educated primparous women in a regional centre were recruited, which limits the generalizability of the data to the rest of Ireland.

\section{Conclusion}

These data from the first Irish birth cohort study and the largest prospective study on complementary feeding to date reveal that breast-feeding initiation rates continue to improve, but breast-feeding duration remains very short. The practice of premature complementary feeding is decreasing and most infants are introduced to complementary foods between 4 and 6 months. Younger, lesseducated mothers are more likely to provide complementary foods before 17 weeks. Due to a lack of agreement among authoritative organizations about the appropriate time to introduce solid foods and what these foods should be, complementary feeding practices vary considerably. The increased use of casein-dominant infant formula as year one progressed, the persistence of cow's milk as a mainstay among $15 \%$ of infants, the use of composite foods (mainly 'infant breakfast cereals') as first foods and lengthy gaps between the introductions of each new food are issues highlighted in the present study.

\section{Acknowledgements}

Acknowledgements: The authors thank the families for their continued support and the Cork BASELINE Birth Cohort Study research team. Financial support: This work was supported by the National Children's Research Centre (NCRC). The NCRC had no role in design, analysis or writing of this article. Conflict of interest: None. 
Authorship: M.K. and S.M.O.D. designed the research. S.M.O.D. collected data. S.M.O.D. constructed the database and conducted data analysis. D.M.M. is the overall Principal Investigator of the Cork BASELINE Birth Cohort study and M.K., L.C.K., J.O.B.H. and A.D.I. are co-Principal Investigators. S.M.O.D. and M.K. drafted the manuscript and M.K. had responsibility for the final content. All authors reviewed and approved the final submission. Ethics of human subject participation: The Cork BASELINE Birth Cohort Study was conducted according to the guidelines laid down in the Declaration of Helsinki and all procedures were approved by the Clinical Research Ethics Committee of the Cork Teaching Hospitals (reference number ECM 5 (9) 01/07/ 2008). The Cork BASELINE Birth Cohort Study is registered at the US National Institutes of Health Clinical Trials Registry (http://www.clinicaltrials.gov; ID: NCT01498965). Written informed consent was obtained at 20 weeks' gestation or at birth.

\section{References}

1. United Nations Standing Committee on Nutrition (2006) 33rd Annual Session, Geneva, Switzerland, 13-17 March 2006. Double Burden of Malnutrition - A Common Agenda. Geneva: UN; available at http://www.unscn.org/ files/Statements/Double_Burden_A_Common_Agenda.pdf

2. World Health Organization (2001) Global Strategy on Infant and Young Child Feeding. The Optimal Duration of Exclusive Breastfeeding. The 54th World Health Assembly. Geneva: WHO; available at http://apps.who.int/gb/archive/pdf_files/ WHA54/ea54id4.pdf

3. Agostoni C, Decsi T, Fewtrell M et al. (2008) Complementary feeding: a commentary by the ESPGHAN committee on nutrition. J Pediatr Gastroenterol Nutr 46, 99-110.

4. American Academy of Pediatrics (2005) Breastfeeding and the use of human milk policy statement. Pediatrics 115, 496-506.

5. American Academy of Pediatrics (2012) Breastfeeding and the use of human milk. Pediatrics 129, e827-e841.

6. Scientific Advisory Committee on Nutrition (2001) Optimal Duration of Exclusive Breastfeeding and Introduction of Weaning. London: SACN; available at http://webarchive. nationalarchives.gov.uk/20140507012657/http://www.sacn. gov.uk/pdfs/sacn_01_07.pdf

7. Department of Health and Children (2003) Department of Health and Children announces policy change in breastfeeding guidelines. Press Release, 5 August. Dublin: Department of Health and Children; available at http://health.gov.ie/blog/ press-release/department-of-health-and-children-announcespolicy-change-in-breastfeeding-guidelines/

8. Department of Health and Children (2005) Breastfeeding in Ireland; A Five Year Strategic Action Plan. Dublin: Department of Health and Children; available at http://www. breastfeeding.ie/uploads/files/ACTIONplan.pdf

9. Tarrant RC, Younger KM, Sheridan-Pereira M et al. (2010) The prevalence and determinants of breast-feeding initiation and duration in a sample of women in Ireland. Public Health Nutr 13, 760-770.

10. Williams J, Greens S, McNally S et al. (2010) Growing Up in Ireland: The Infant and Their Families. Dublin: Department of Health and Children; available at http://www.growingup. ie/index.php?id=61

11. Lennox A, Sommerville J, Ong K et al. (2011) Diet and Nutrition Survey of Infants and Young Children. London:
Department of Health and Food Standards Agency; available at https://www.gov.uk/government/uploads/system/ uploads/attachment_data/file/139572/DNSIYC_UK_report_ ALL_chapters_DH_V10.0.pdf

12. McAndrew F, Thompsom J, Fellows L et al. (2012) The Infant Feeding Survey 2010. http://www.hscic.gov.uk/ catalogue/PUB08694/Infant-Feeding-Survey-2010-ConsolidatedReport.pdf (accessed October 2014).

13. Foote KD \& Marriott LD (2003) Weaning of infants. Arch Dis Child 88, 488-492.

14. Williams AF \& Prentice A (2011) Scientific Advisory Committee on Nutrition replies to Mary Fewtrell and colleagues. BMJ 342, d980.

15. Fewtrell M, Wilson DC, Booth I et al. (2010) Six months of exclusive breast feeding: how good is the evidence? BMJ 342, c5995.

16. Fergusson DM, Horwood LJ, Beautrais AL et al. (1981) Eczema and infant diet. Clin Allergy 11, 325-331.

17. Fergusson DM, Horwood LJ \& Shannon FT (1982) Risk factors in childhood eczema. J Epidemiol Community Health 36, 118-122.

18. Fergusson DM, Horwood LJ \& Shannon FT (1990) Early solid feeding and recurrent childhood eczema: a 10-year longitudinal study. Pediatrics 86, 541-546.

19. Greer FR, Sicherer SH, Burks AW et al. (2008) Effects of early nutritional interventions on the development of atopic disease in infants and children: the role of maternal dietary restriction, breastfeeding, timing of introduction of complementary foods, and hydrolyzed formulas. Pediatrics 121, 183-191.

20. Fleischer DM, Spergel JM, Assa'ad AH et al. (2013) Primary prevention of allergic disease through nutritional interventions. J Allergy Clin Immunol Pract 1, 29-36.

21. de Silva D, Geromi M, Halken S et al. (2014) Primary prevention of food allergy in children and adults: systematic review. Allergy 69, 581-589.

22. Tarrant RC, Younger KM, Sheridan-Pereira M et al. (2010) Factors associated with weaning practices in term infants: a prospective observational study in Ireland. Br J Nutr 104, $1544-1554$.

23. Groom KM, North RA, Stone PR et al. (2010) Patterns of change in uterine artery Doppler studies between 20 and 24 weeks of gestation and pregnancy outcomes. Obstet Anesth Digest 30, 52-53.

24. Chappell LC, Seed PT, Myers J et al. (2013) Exploration and confirmation of factors associated with uncomplicated pregnancy in nulliparous women: prospective cohort study. BMJ 347, f6398.

25. North RA, McCowan LME, Dekker GA et al. (2011) Clinical risk prediction for pre-eclampsia in nulliparous women: development of model in international prospective cohort. BMJ 342, d1875.

26. O'Donovan SM, Murray DM, Hourihane JOB et al. (2014) Cohort profile: the Cork BASELINE Birth Cohort Study: babies after SCOPE: evaluating the longitudinal impact on neurological and nutritional endpoints. Int $J$ Epidemiol (Epublication ahead of print version).

27. Health Service Exceutive (2009) Starting to spoonfeed your baby. http://www.healthpromotion.ie/hp-files/docs/HPM0 0381.pdf (accessed April 2013).

28. Food Safety Authority of Ireland (1999) Recommendations for a National Infant Feeding Policy. Dublin: FSAI; available at http://www.fsai.ie/search-results.html?searchString= infant $\% 20$ feeding\%20policy $\% 201999$

29. Health Research and Information Division, Economic and Social Research Institute (2012) Perinatal Statistics Report 2010. Dublin: ESRI; available at http://www.esri.ie/news_ events/latest_press_releases/perinatal_statistics_repo_4/

30. Central Statistics Office Ireland (2006) Census 2006: Education and Qualifications. Dublin: Central Statistics 
Office Ireland; available at http://census.cso.ie/census/ ReportFolders/ReportFolders.aspx

31. Food Safety Authority of Ireland (2011) Scientific Recommendations for a National Infant Feeding Policy. Dublin: FSAI; available at http://www.fsai.ie/news_centre/press_ releases/infant_feeding_19112012.html

32. Planning Unit Department of Health (1990) Perinatal Statistics Reports: 1990. Dublin: The Stationery Office; available at http://www.lenus.ie/hse/bitstream/10147/242294/1/Perinatal $\% 20$ statistics\%

33. Department of Health and Children (1994) A national breastfeeding policy for Ireland. http://www.dohc.ie/ publications/national_breastfeeding_policy.html (accessed October 2014).

34. National Health Service (2013) Hospital Episode Statistics. NHS Maternity Statistics - England, 2012-2013. http:// www.hscic.gov.uk/catalogue/PUB12744/nhs-mate-eng2012-13-summ-repo-rep.pdf (accessed February 2015).

35. Begley C, Gallagher L, Clarke M et al. (2008) The National Infant Feeding Survey 2008. Dublin: Trinity College Dublin, School of Nursing and Midwifery; available at http://www. breastfeeding.ie/uploads/files/National_Infant_Feeding Survey_2008.pdf

36. UNICEF UK, The Baby Friendly Initiative (2014) The Health Professional's guide to: 'A guide to infant formula for parents who are bottle feeding'. London: UNICEF UK; available at http://www.unicef.org.uk/Documents/Baby_Friendly/Leaflets/ HP_Guide_for_parents_formula_feeding.pdf

37. Tarrant RC, Sheridan-Pereira M, McCarthy RA et al. (2013) Mothers who formula feed: their practices, support needs and factors influencing their infant feeding decision. Child Care Pract 19, 78-94.

38. Hopkins D, Emmett P, Steer C et al. (2007) Infant feeding in the second 6 months of life related to iron status: an observational study. Arch Dis Child 92, 850-854.
39. Wright CM, Parkinson KN \& Drewett RF (2004) Why are babies weaned early? Data from a prospective population based cohort study. Arch Dis Child 89, 813-816.

40. Twomey A, Kiberd B, Matthews T et al. (2000) Feeding infants - an investment in the future. Ir Med $J \mathbf{9 3}$, $248-250$

41. Grimshaw KEC, Maskell J, Oliver EM et al. (2013) Introduction of complementary foods and the relationship to food allergy. Pediatrics 132, e1529-e1538.

42. Coulthard H, Harris G \& Emmett P (2010) Long-term consequences of early fruit and vegetable feeding practices in the United Kingdom. Public Health Nutr 13, 2044-2051.

43. Department of Health (2003) Infant Feeding Recommendation. London: Department of Health; available at http:// webarchive.nationalarchives.gov.uk/20130107105354/http:// www.dh.gov.uk/prod_consum_dh/groups/dh_digitalassets/ @dh/@en/documents/digitalasset/dh_4096999.pdf

44. European Commission (2007) Foods for Infants \& Young Children - Cereals and other baby foods. http://ec.europa. eu/food/food/labellingnutrition/children/baby_food_en.htm (accessed January 2007).

45. Muraro A, Halken S, Arshad SH et al. (2014) EAACI Food allergy and anaphylaxis guidelines. Primary prevention of food allergy. Allergy 69, 590-601.

46. Moore AP, Milligan P, Rivas C et al. (2012) Sources of weaning advice, comparisons between formal and informal advice, and associations with weaning timing in a survey of UK first-time mothers. Public Health Nutr 15, 1661-1669.

47. Savage SH, Reilly JJ, Edwards CA et al. (1998) Weaning practice in the Glasgow Longitudinal Infant Growth Study. Arch Dis Child 79, 153-156.

48. Alder EM, Williams FLR, Anderson AS et al. (2004) What influences the timing of the introduction of solid food to infants? Br J Nutr 92, 527-531. 